\title{
Além da música: repensando Sgt. Pepper's Lonely Hearts Club Band
}

\author{
Sarah A. Etlinger (University of Winsconsin, Milwaukee, EUA) \\ etlinger@uwm.edu
}

Tradução de Fausto Borém (UFMG, Belo Horizonte, MG)

fborem@ufmg.br

\begin{abstract}
Resumo: A discussão crítica sobre o Sgt. Pepper's Lonely Hearts Club Band tem sido consistentemente consolidada em relação à importância do álbum, especialmente em relação às inovações musicais e maneiras com que mudou a cultura do rock. Quando se menciona a capa do álbum, esta é analisada em termos de sua relação simbólica com o conteúdo das inovações musicais do disco. Entretanto, teóricos como Kenneth Womack e Todd F. Davis examinaram a relação dos Beatles com a teoria crítica, enquanto que lan Inglis explora o trabalho cultural contido nas capas dos álbuns dos Beatles. Ao invés de tratar da relação música e imagem, este artigo busca expandir a discussão além de seu valor para a música popular, focando em três contextos visuais: pop art, fotomontagem e a história do design em capas de álbuns. Defendo, no presente artigo, que Sgt. Pepper marca uma mudança na maneira como a imagem da banda desempenha uma crítica auto-reflexiva, tanto por meio do conteúdo visual da imagem quanto nos processos pelos quais foi criada, o que faz a capa do álbum transcender um simples bem de consumo ou uma embalagem exótica. A confluência entre pop art e fotomontagem e permeia essa discussão, uma vez que ambos movimentos estão engajados com a questão da representação e o status quo por meio da apropriação de imagens da comunicação de massa.
\end{abstract}

Palavras chave: Sgt. Pepper's Lonely Hearts Club Band; pop art em capas de discos; fotomontagem e representação visual.

\section{Beyond the music: rethinking Sgt. Pepper's Lonely Hearts Club Band}

Abstract: The critical discussion of Sgt. Pepper's Lonely Hearts Club Band has consistently been framed in terms of its importance as a record album. That is, remarks about its musical innovations and the ways it changed the culture of rock music dominate the conversation. When the album cover is mentioned, it is analyzed in terms of the symbiotic relationship it has with the musical innovation of the album itself. However, the discussion is changing; theorists Kenneth Womack and Todd F. Davis have examined the Beatles' relationship to critical theory, and music critic lan Inglis explores the cultural work of the Beatles' album covers. Yet much of this criticism still focuses primarily on the relationship between music and image. In this paper I expand the discussion beyond its value to popular music and consider the album cover in three visual contexts: Pop Art, photomontage, and the history of album cover design. I argue that Sgt. Pepper marks a shift in how the image of the band performs a self-reflexive critique, both through the visual content of the image as well as the processes by which it was created. This destabilizes the album cover as a mere commodity or extraneous packaging. The confluence of Pop Art and photomontage enhances the critique, for these movements fundamentally engage with problematizing representation and the status quo through the appropriation of mass mediated images.

Keywords: Sgt. Pepper's Lonely Hearts Club Band; pop art in album covers; photomontage and visual representation.

Agradecimento: A revista Per Musi agradece às Editions Seteun, por permitir a tradução desse artigo, originalmente publicado em inglês na revista Volume! La Revue de musiques populaires, v.8, n.1, 2011. p.253-276. Acesso gratuito em http://volume.revues.org/1305. 


\section{1 - A produção da capa de Sgt. Pepper's}

Uma busca rápida na internet sobre o Sgt. Pepper's Lonely Hearts Club Band (1967) revela dezenas de milhares de pontos de busca. Todos levam a duas categorias: primeiro, um projeto musical com inovações jamais alcançadas que provocou enormes mudanças na indústria da música; segundo, um símbolo dos Beatles e da cultura dos anos de década de 1960. De toda maneira, a prevalência deste tipo de imagem forma um arcabouço que permite compreender não apenas a relevância dos Beatles, mas do próprio Sgt. Pepper's Lonely Hearts Club Band. De todos os projetos dos Beatles, este foi o que mereceu mais tempo de difusão na mídia e na imprensa do que qualquer outro. É amplamente considerado um álbum "pioneiro" em muitos aspectos: a primeira capa dupla de $L P$, o primeiro álbum a incluir letras de canções na capa, o primeiro" álbum conceito", o primeiro álbum a declarar abertamente um envolvimento com o psicodelismo liberal da década de 1960 (HARRY, 1992, p.970). Quaisquer que sejam as razões, uma coisa é certa: Sgt. Pepperse tornou o padrão dourado dos músicos, elevando o nivel de referência para as inovações musicais e a distinta arte das capas de discos.

Qualquer leitura sobre Sgt. Pepper's Lonely Hearts Club Band parece gravitar em torno de sua ambiguidade [Nota do tradutor: leia, às p.187-200 do presente volume de Per Musi, uma resenha sobre trecho que trata desse álbum no livro The Lives of John Lennon de Albert Goldman]. Ou seja, o sentido de confusão que permeia os anos de 1960 a 1970 aparentemente escoou para as análises de seus artefatos culturais. Digo isto porque os críticos, ao abordarem Sgt. Pepper, apontam para o modo em que o álbum encarapita sobre duas posições sociais de uma só vez: como peça da cultura pop, mas também como um texto intelectualmente provocativo e obviamente político. Quando os estudiosos o examinam, tendem a privilegiar as inovações musicais em detrimento dos elementos visuais. Em Covering music: a brief history and analysis of album cover design, Martim SORGER e Steve JONES (1999, p.68) lamentam a escassez de estudos sobre as capas de álbuns, observando que elas "nunca são compreendidas em termos puramente funcionais, ou como uma forma de design gráfico". Comentando que "a música, cada vez mais, dependeu do estilo visual para se apresentar e se vender", esses autores examinam amplamente as condições de produção das capas de álbuns desde sua emergência na década de 1930 como capas protetoras para os discos, chamadas de "slicks" até a proliferação de grafismo e complexos elementos de design na década de 1960. Eles identificam o surgimento do LP (disco longplaying) em 1948 como o momento em que as capas de álbuns de tornaram um elemento importante na indústria fonográfica. Um outro fator importante no surgimento das capas de disco foi a conexão entre os primórdios do rock e o cinema. Muitos ícones da música popular, como Elvis Presley, também eram astros do cinema e as capas de álbuns eram utilizadas como ferramentas promocionais para os filmes - essencialmente fotos das estrelas - para melhorar o seu design.
SORGER e JONES (1999, p.68) identificam a fotografia como um elemento chave no design das capas dos discos: a natureza representacional deste meio se encaixa como uma luva nos seus propósitos, como lan INGLIS (2001, p.83) observa em Nothing you can see can't be shown: the album covers of the Beatles: servem de proteção para a gravação, de acompanhamento para a música, de propaganda para o grupo musical, são um objeto de compra e um investimento. A fotografia se tornou uma ferramenta na comercialização da banda musical, oferecendo-a como um bem de consumo duradouro. Assim, as capas de discos representam a banda e a música que estão ali dentro. A banda toca a música, mas como não podemos comprar a banda, compramos sua representação na forma de uma fotografia na capa do disco. Entretanto, SORGER e JONES $(1999$, p.77) observam que a grande dependência da fotografia começou a decair ao final da década de 1960. Ao mesmo tempo em que a cultura psicodélica levou à arte psicodélica, "a fotografia seguiu a ilustração e a colagem, explorando novas utilizações e combinações. Imagens enigmáticas passaram a substituir a natureza informativa e documentária presente na típica capa de álbum fotográfica". Esses autores perceberam essa mudança como fundamental, pois ela iniciou a tendência atual que se tornou marcante com Sgt. Pepper's Lonely Hearts Club Band, não apenas porque incorporou diversos elementos visuais no seu design, mas também porque não mais se atrelou à "natureza informativa e documentária" da fotografia (veja a foto, croqui e nomes dos personagens dessa capa nos Ex.3, 4 e 5, às p.195-197 desse número de Per Musi). Ao contrário, como afirmam esses autores, Sgt. Pepper foi calcado na subversão e mudança de figuras familiares.

Podemos ver como Sgt. Pepper muda a maneira de vermos a fotografia olhando para o grupo de pessoas no plano de fundo. ${ }^{1}$ Antes deste álbum revolucionário, as fotos dos membros das bandas, incluídos aí os Beatles, invariavelmente ocupavam o centro. As imagens dos membros da banda ajudavam a solidificar a conexão entre a música e a banda; elas davam "uma cara" para a experiência de ouvir. Serviam também para estampar uma "marca" da música. Os consumidores de discos aprenderam a associar os quatro Beatles - e seus cortes de cabelo de franjinhas desgrenhadas ou de botinhas e ternos sem colarinhos - coma música que produziam. De certa forma, a dependência das capas dos discos da fotografia confundia a relação entre a música e a imagem em um ponto sem retorno: era virtualmente impossivel não associá-la imediatamente a risada charmosa de Paul McCartney com sua performance brincalhona e açucarada em All my loving. Entretanto, Sgt. Pepper quebra esta noção ao não mostrar, em nenhum lugar da capa, uma fotografia dos Beatles. Embora eles apareçam em duas representações diferentes na capa, eles são representados como bonecos de cera - representações tridimensionais que imediatamente contrastam com as fotografias bidimensionais logo atrás deles enquanto que os Beatles "reais" ficam em pé no centro 
da pequena multidão. Além disso, os Beatles "reais" estão disfarçados como membros da banda fictícia do Sgt. Pepper's Lonely Hearts Club, vestindo macacões de cetim neon. Ambas as representações dos Beatles contrastam distintamente com as silhuetas recortadas em papelão de aspecto quase fantasmagórico de seus "heróis", parecendo sugerir as limitações da fotografia em termos de sua habilidade tecnológica de representar a realidade. As fotografias recortadas dos heróis do passado e do presente não oferecem a mesmo tipo de identificação imediata e fácil que o reconhecimento dos Beatles permite. Ao contrário, os Beatles estão quase perdidos em um mar de gente, deixando o expectador se perguntando de quem seria aquele álbum. A grande complexidade da imagem, por si só, requer um tipo de relação diferente entre observador e imagem, entre álbum e banda, entre representação e identidade.

Ian Inglis chama nossa atenção para a complexidade intelectual por meio dos excessos visuais do álbum. Julgar Sgt. Pepper como um "momento decisivo na história da civilização ocidental" (INGLIS, 2001, p.87) enfatiza sua importância como uma "correspondência visual-musical formidável". Além de outras inovações, ele descreve a capa como a primeira a "especificamente se oferecer como um objeto para investigação explícita; identificar as figuras [. . . ] apresentadas no retábulo se torna um jogo popular e um exercício intelectual" INGLIS (2001, p.92). Para ele, um dos maiores significados de Sgt. Pepper's Lonely Hearts Club Band está na maneira como convida o observador/ouvinte a entrar no álbum. Identificar as figuras requer um olhar ativo e escrutínio que, por sua vez, requer que o observador assuma uma posição pessoal diante da imagem, ao invés de ignorá-la passivamente como um acessório à musica que contem. De certa maneira, a análise de Inglis nos faz acreditar que, depois de Sgt. Pepper, as capas de álbuns poderiam se tornar muito mais que um acompanhamento para a música; se tornaram críticas sociais, políticas e culturais que passaram a requerer um envolvimento por parte do público.

0 estudo de Inglis introduz três maneiras de leitura da capa do álbum que convidam a reflexões posteriores sobre as inovações visuais de Sgt. Pepper: como texto visual, como links entre a imagem visual e a música e como marcadores influentes na comunidade musical. Uma vez que já existem diversos trabalhos realizados sobre as duas últimas categorias, as deixo de lado para considerar apenas o álbum como texto visual. Com esse foco, Sgt. Pepper confere novas identidades à banda como participante dos movimentos subculturais cada vez mais presentes na década de 1960. Dadas as duas representações dos Beatles na capa, podemos entender que Sgt. Pepper marca a "ruptura definitiva com a indústria da música pop" pelos Beatles (INGLIS, 2001, p.87). Sob este prisma, a capa do álbum, enquanto texto visual, apresenta um tipo de autocrítica, tanto como um bem de consumo quanto uma representação de identidade da banda.
A compreensão dos Beatles sobre sua própria identidade cultural, como pop stars e artistas de raízes nas classes trabalhadoras, ajuda a compreender o valor de Sgt. Pepper como texto visual. Tomando emprestada a leitura que Kenneth Womack e Todd F. Davis fazem em Mythology, remythology and demythology: The Beatles on film, a capa do álbum mostra os egos mitológicos anteriores dos Beatles em pé à direita de seus correspondentes contemporâneos remitologizados, e estes rodeados de figuras também remitologizadas, dos anais da história, da religião, de Hollywood, da música, dos esportes e da literatura (WOMACK, DAVIS, 2006, p.104). Os autores também observam que essas representações "remitologizadas ... prefiguram as novas identidades mitologizadas que o grupo [mais tarde] traria para a realidade" (WOMACK, DAVIS, 2006, p.104). Quando Womack e Davis se referem à "mitologia", se referem à manipulação autônoma e consciente de identidades culturais particulares - sejam eles super ícones da indústria pop ou pioneiros da contracultura psicodélica - com o objetivo de expor sua óbvia cumplicidade e rejeição a essas identidades. Resumindo, Womack e Davis sugerem que os Beatles passaram por três estágios nos quais sua identidade estava em risco, e que eles reestruturaram estas identidades ativamente de acordo com os projetos em cada época. Invoco esses autores porque acredito que é deles o trabalho que mais efetivamente aborda o tipo de crítica que almejo, embora com a ressalva de que aposta todas as suas fichas na interação entre a música e a capa do álbum.

\section{2 - Fotomontagem e a crítica auto reflexiva da representação}

Nesta seção, tratarei especificamente da imagem em relação às condições de sua produção. Basicamente, o processo e origem da imagem aponta para as maneiras com as quais comunicam sua mensagem. Porque a capa representa a performance em dois níveis - conceitual e visual - a capa do álbum encena uma crítica da representação. Conceitualmente, o concerto encenado na capa do álbum coloca os Beatles como performers e como membros de uma plateia. A capa foi concebida como substituta para um concerto, que seria dado por uma banda fictícia, a Sgt. Pepper's Lonely Hearts Club Band. Sendo um evento encenado, os Beatles estavam literalmente vendendo uma representação de sua performance imaginária. Visualmente, entretanto, a imagem mostra a performance de uma fotografia e uma representação visual por meio de uma colagem de pessoas agrupadas em torno dos Beatles. Intitulada Gente que eu gosto, a imagem do grupo de pessoas é feita de fotografias em tamanho real, coladas em papelão e recortadas, depois arranjadas e fotografadas contra um fundo azul. Ao usar uma fotografia da fotografia (que na época já era um processo de produção em série), a capa do álbum é uma representação da representação. Como um todo, entretanto, marca uma guinada na maneira como a representação desempenha um importante papel para compreender a importância das capas de álbum em geral. 
Sgt. Pepper nos fala de como a imagem da banda se tornou mais performática na capa do álbum, refletindo um engajamento autoreflexivo com a representação visual em um tipo de autocrítica jocosa. A crítica abrangente da representação também desestabilizou a noção de capa de álbum como simples mercadoria embora o próprio Sgt. Pepper tenha se engajado também ao incluir os recortes de personalidades e comercializar o álbum como um pacote. A influência da pop art e da fotomontagem, enquanto elementos essenciais de design da imagem, também funcionam como desestabilizadores da conexão da capa do álbum com o bem de consumo, uma vez que ambos, pop art e da fotomontagem, já eram movimentos artísticos de vanguarda alinhados com a esquerda cultural. E como esses movimentos artísticos de vanguarda estavam incorporados como elementos intrínsecos da capa do álbum, a imagem tem ainda outra camada de complexidade da crítica da representação e do bem de consumo. Em geral, a combinação da própria visão artística dos Beatles com a progressiva popularidade permitiu às capas de álbuns se tornarem lugares para a crítica cultural. Por meio da exploração desses contextos, assim como a relação de Sgt. Pepper com a história do design de capas de álbuns, pretendo mostrar que as capas de álbuns devem ser consideradas separadamente de seu valor musical, como lugares de crítica cultural, política e social, ou seja, devem ser lidas separadamente de sua excessiva associação com a música popular.

Paul McCartney nos dá a melhor descrição do tema do álbum: "Porque não pensar o álbum inteiro como se a Pepper Band realmente existisse, como se o Sgt Pepper estivesse, de fato, gravando um disco?" (HARRY, 1992, p.970). Harris defende que McCartney é quem concebeu a ideia de ter "um monte de celebridades, mortas ou vivas, dispostas na capa do álbum" (HARRY, 1992, p.970). Embora Brian Epstein, empresário dos Beatles, e o produtor George Martin estivessem céticos no início, os Beatles insistiram e o resultado foi, na fala eloquente de HARRY (1992, p.971), "a capa mais famosa de qualquer tipo de música e uma das mais imitadas imagens de todo o mundo". Para esta capa histórica, os Beatles reuniram os fotógrafos Robert Fraser (que já havia se tornado famoso com outras capas dos Beatles) e Michael Cooper, e o artista pop Peter Blake. Blake havia feito uma peça para os Beatles no início dos anos de 1960 (LEVY, 1963, p.185) e era conhecido por suas colagens interessantes sobre ícones populares como Marilyn Monroe e Elvis Presley. 0 time formado por Blake e Cooper pediu aos Beatles que listassem seus 12 heróis mais populares da história. $A$ lista engordou, chegando a quase 70, 60 dos quais foram incluídos na capa.

A fotomontagem das celebridades talvez seja o elemento mais famoso da capa, embora apresente diversas outras características interessantes. Um bumbo decorado e com o nome "Sgt. Pepper's Lonely Hearts Club Band" ocupa o centro da imagem. 0 grupo de pessoas está flanqueado por imagens de cera, estátuas de jardim, um arranjo floral no qual se lê "Beatles" 2 e outra na forma de um violão, uma boneca, uma boneca de pano de Shirley Temple e vasos de pepperonia (HARRY, 1992, p.977-978). Com tudo isso, a capa apresenta um mural complexo, misturando fotografia, objetos, figuras e mesmo, tecido (os uniformes psicodélicos que os Beatles estão usando como se fossem membros da Sgt. Pepper Band). Essa complexidade visual sugere que a imagem da capa não fazia parte de um pacote descartável, mas um artefato visual preparado para um público cada vez mais seletivo e crítico. Em resumo, esta capa representa a primeira tentativa dos Beatles de se engajarem com seus fãs de um modo complexo.

Como observaram muito críticos e estudiosos do Beatles, eles estavam cansados de viajar em turnê por volta do final de 1965. Ainda assim, se comprometeram com diversas turnês e concertos em 1966, com resultados cada mais catastróficos. Depois do seu último show no Shea Stadium [em Nova lorque] em agosto de 1966, no qual os Beatles quase foram eletrocutados em uma tempestade de verão e se sentiram acossados por fãs agitados e aos gritos, eles decidiram abandonar aquele estilo de vida. Se voltaram para a rotina dos estúdios e, assim, nasceu Sgt. Pepper. HARRY (1992, p.969) observa que o álbum se tornou o que é porque os Beatles passaram a ter mais tempo para desenvolver e amadurecer o artesanato de sua música, uma vez que não se sentiam mais pressionados a produzir hits para shows ou serem interrompidos por outros compromissos. Mas as longas horas no estúdio não significavam que os Beatles se esqueceram de seus fãs. Muitas acreditam que, nessa época, foi um período em que mais tinham seu público em mente.

Podemos ver evidência disto no conceito do álbum. 0 próprio fato dos Beatles estarem encenando um concerto fictício com uma banda fictícia reflete sua consciência sobre a importância cada vez maior da performance e música ao vivo. Mais do que isso, podemos argumentar que o design da capa - no qual as pessoas estão encarando a público - se apresenta como algo pra ser notado: uma performance, uma interação com a audiência. William M. NORTHCUTT (2006, p.130-131) mostra a relação entre "a multidão" que ilustra a capa e os observadores em The Spectacle of alienation: death, loss and the crowd in Sgt. Pepper's Lonely Hearts Club Band, observando que parte da importância cultural do álbum é que ele "ajudou a perpetuar a ideia de que o verão de 1967 foi um momento único de unidade social", mas que, na verdade, os Beatles tinham uma relação cada vez mais antagônica com a multidão de seus fãs: "em Sgt. Pepper, Lennon, McCartney, Harrison e Starr se retraem de seu público que já os constrangia com a Beatlemania e os ataques aos Beatles". Ele argumenta que esta complexa relação inaugurou uma "crise de identidade, a qual os Beatles tentaram resolver com Sgt. Pepper - por meio de novas 'leituras' de suas influências musicais, novos ideais filosóficos descobertos recentemente, a emergente cultura das drogas e o mundo que eles queriam mudar". 
Essencialmente, Northcutt nos assegura que o álbum "trata tanto de separação e alienação quanto de unidade".

Northcutt também fala do papel das massas como uma componente central da mensagem geral de Sgt. Pepper. Ele classifica os vários significados das massas: a massa dos compradores de discos, a massa dos beatlemaníacos - que "compra discos, mas torna o contato real e a música real impossíveis" - a massa dos "conhecedores das elites, apreciadores de arte e fãs de rock $n^{\prime}$ roll que estavam ligados no "sentir a vibrações" e "ignorantes, moral e politicamente hipócritas, apoiadores, e repetidores de costumes e leis restritivas" - essencialmente, o establishment proverbial e seus agentes. Essa classificação demonstra a complexidade do público para o qual os Beatles estavam se apresentando e articula as muitas camadas de identidade com as quais os Beatles tinham de lidar quando expunham sua crítica. Em outras palavras, os Beatles estavam conscientes do público para o qual se apresentavam. E incorporaram esta consciência na capa do disco. Talvez a melhor evidência disso é a variedade de pessoas representadas como seus heróis. Discutirei o significado desse tableau em conjunto com a fotomontagem, que foi o meio escolhido para construí-lo.

Não chega a surpreender que as mudanças e inovações em arte resultam de mudanças no clima político. Nos seus primórdios, o Cubismo reflete uma mudança na percepção muito em função dos avanços no cinema, indústria e transportes - distorcendo a realidade e, como resultado, as suas perspectivas. Quando a Primeira Guerra Mundial terminou, entretanto, mesmo esse tipo de representação produzida com pintura e materiais do cotidiano, se mostrou inadequada porque representava a destruição da realidade e a emergência de ideologias sociais penetrantes. A fotomontagem não é uma exceção a esta regra. No seu trabalho seminal sobre foto montagem, Dawn ADES (1976, p.12) traça o nascimento deste movimento impressionantemente complexo enquanto um subconjunto do movimento Dada em Berlin e na União Soviética. Ades credita seu desenvolvimento às mudanças de perspectiva na relação entre arte e realidade, o que ela descreve como "um reconhecimento de uma atitude, com a qual todos [os dadaístas] compartilhavam em relação às suas obras e sua relação com hierarquias artísticas existentes". Essa atitude resulta de uma consciência na qual as pinturas podiam ser "compostas inteiramente de recortes de fotografias. . . [de forma que] a imagem comunicaria de uma forma nova" (ADES, 1976, p.20). Ele observa que a prática da fotomontagem havia se associado anteriormente com os cartões postais (os quais combinavam diferentes imagens fotográficas, texto e imagens desenhadas) e com o desenvolvimento da fotografia durante a Primeira Guerra Mundial; "vistas aéreas, microscópios e radiografias". Mas Ades enfatiza que a fotomontagem geralmente se origina de

"[. . .] uma necessidade urgente de se afastar das limitações da abstração sem retornar aos modos ilustrativos e figurativos antiquados. A fotografia, obviamente, tem um lugar especial e privilegiado na relação com a realidade; realidade que é susceptivel à manipulação para reorganizar e desorganizar aquela realidade. Por esta razão, foi na Rússia e em Berlim, onde o ímpeto para se afastar de movimentos predominantemente estético de cunho social foi muito marcante, que a fotomontagem surgiu (ADES, 1976, p.66).

Essencialmente, o turbilhão político terraplanou o terreno para a ruptura e manipulação da realidade fotográfica. ADES observa que a fotomontagem estava se tornando cada vez mais popular "em todas as facções políticas da Europa e Rússia nas décadas antes da Segunda Guerra Mundial", embora seja comumente associada com a política de esquerda por ser "idealmente apropriada à expressão da dialética marxista" (ADES, 1976, p.41). Ela credita a natureza "real" da fotografia como a força motora por trás de sua utilização política em Berlim e na Rússia durante os anos que se seguiram à Primeira Guerra Mundial. Como havia uma aparente necessidade de rejeitar os modos figurativos, a fotografia se tornou um veículo político. Essas colagens políticas eram extraordinariamente acessiveis, promovendo uma correlação dolorosamente clara entre imagem e objeto, ou imagem e mensagem. Citando Gustav Klutsis, Ades estabelece uma conexão entre a fotomontagem e "o desenvolvimento da indústria cultural e das mídias de cultura de massa" (ADES, 1976, p.63), o que sugere sua concordância com as tendências politicas esquerdistas, e explica sua associação com a cultura de massa, consciência de classes e insatisfação com as agendas políticas opressoras. Qualquer que seja o caso, as mudanças de percepção provocadas por mudanças de realidade desempenharam um importante papel na formação de um movimento que continuaria a metamorfosear os mundos político e artístico durante décadas.

Uma quintessência da fotomontagem é a justaposição de imagens para "revelar a ideologia pelo que ele é, revelando a estrutura de classe das relações sociais ou escancarando a ameaça do fascismo" (ADES, 1976, p.45). Diferentemente da colagem, que agrupa artefatos, fotografia e outras imagens ou objetos para enriquecer a textura de um trabalho artístico, a fotomontagem combina várias fotografias e as distorce, ou monta um quadro se baseando estritamente em imagens "encontradas". Uma definição simples de fotomontagem é "fotografia manipulada", mas não dá conta da variedade de usos ou práticas dessa técnica. Cortar e colar são duas de suas técnicas básicas. Assim, muitas vezes as obras parecem amontoadas, distorcidas e caóticas. ADES (1976, p.17) argumenta que obras de fotomontagem "transformam as relações entre objetos familiares, transgridem a escala, sugerem estranhos efeitos espaciais." John Berger (citado por ADES, 1976, p.48) também caracteriza esta sensação com clareza no seu ensaio The Political uses of photomontage, observando que "a vantagem peculiar da fotomontagem se deve ao fato de que tudo que foi recortado mantem sua aparência fotográfica familiar. Primeiro, olhamos para as coisas e somente depois elas são percebidas como símbolos" (ADES, 1976, p.48). Essa asserção diz respeito ao constante diálogo entre as coisas e sua representação, entre objeto e símbolo presente na fotomontagem. 
Particularmente, a afirmação de Berger se aplica à feitura de Sgt. Pepper, uma vez que os recortes em tamanho real são simples fotografias que representam ou, em alguns casos, apenas lembram seus correspondentes na "vida real". Alguns parecem mesmo não identificáveis ${ }^{3}$ escolhas esotéricas feitas pelos membros da banda - ou estão obscurecidos por outros recortes. De uma maneira geral, entretanto, a inclusão de diversas imagens sugere não apenas uma crítica da habilidade da fotografia de "narrar" ou representar a realidade (como mencionei, os Beatles não estavam encenando um evento "real"), mas também uma crítica de seu valor na sociedade. Como veremos, uma análise mais detalhada do papel da fotomontagem na capa do álbum mostra como ela atrai a atenção para as diversas camadas de representação com a função de complicar a identidade dos Beatles enquanto ícones populares. De fato, podemos perceber a utilização da fotomontagem como crítica da própria identidade, como se os Beatles estivessem tentando se remodelar, juntamente com a capa do álbum, como para uma mudança social e política, assim como uma maneira de acessar essa mudança. A fotomontagem nos permite criticar os discursos de identidade, representação, performance e realidade. Sua utilização maciça nesse caso, nos permite considerar que a capa realiza os mesmos o tipos de crítica.

Não há dúvida que a capa de Sgt. Pepper faz sua crítica da representação em diversos níveis, embora o mais importante para nós seja a justaposição do grupo de pessoas com as duas representações do Beatles. As primeiras imagens dos Beatles são modelos de cera do museu de Madame Tussaud, que se posicionam adjacentes aos Beatles "reais", embora esses Beatles estejam vestindo uniformes militares de seda, psicodélicos. Imediatamente, o observador vê o contraste entre os Beatles de terno e com corte de cabelo de franjinha ("moptop") - fantasmas de uma época dos Beatles que passou - e sua repetição no presente. NORTHCUTT (2006, p.132) sugere que este contraste marca a passagem de performers para artistas, de bonecos de cera para pessoas de verdade. Entretanto, do ponto de vista de nossa discussão, gostaria de acrescentar outra ideia: a de representação. Se considerarmos as duas versões dos Beatles em relação ao grupo de pessoas na fotomontagem, surge aqui uma crítica com outra nuança que permite, de fato, quase requer, considerações políticas. Especificamente, a utilização da fotomontagem nos permite ver a banda como parte de uma consciência política que começa a se formar (NORTHCUT, 2006, p.129) e que começa a derrubar as barreiras entre a arte de alto nível e a arte popular (NORTHCUTT, 2006, p.135).

A capa justapõe figuras políticas (como T.E. Lawrence, Karl Marx, Gandhi, Einstein, e Carl Jung) com artistas e animadores culturais como Tony Curtis, Mae West, Lenny Bruce, Bob Dylan, Marilyn Monroe e Sonny Liston. A capa também inclui escritores como W.C. Fields, Oscar Wilde e Aubrey Beardsley. Esta variedade funciona de duas maneiras pra comunicar a crítica política da representação. Primeiro, a combinação de figuras políticas mais populares com heróis da política e da cultura derruba - ou, na melhor as hipóteses, desestabiliza - o status das figuras de "elite". Também destrói o senso de história "real". Karl Marx não é um contemporâneo de Tony Curtis ou mesmo Oscar Wilde mas, ainda assim, aparece na capa com o mesmo tipo de valor cultural a ele designado. Em Reading an Archive [Lendo um arquivo], Allan SEKULA (1987, p.116) apresenta uma maneira satisfatória de como isto ocorre: "No arquivo, a possibilidade de se ter um significado é 'liberada' de suas contingências reais de uso. Mas esta liberação também se perde, se torna uma abstração da complexidade e riqueza de sua utilização, há uma perda de conteúdo. Assim, a especificidade das utilizações e significados 'originais' pode ser evitada e, mesmo, ser escondida, quando fotografias são selecionadas de um arquivo e reproduzidas em um livro". Em outras palavras, o arquivo necessariamente "apaga" os valores sociais, políticos ou culturais das imagens originais, pois a justaposição impõe o que ele chama de "equivalência visual abstrata" (SEKULA, 1987, p.117). No caso de Sgt.Pepper, Peter Blake e Robert Fraser assumiram a responsabilidade de criar as fotografias e o museu de cera de Madame Tussaud se encarregou de prover as figuras de cera dos Beatles - as quais não apenas a capa, mas as recepções e interpretações da capa, apagam.

Podemos ver evidências da "equivalência visual abstrata" de Sekula, quando examinamos o status das figuras na capa do álbum. Basicamente, o status das figuras é ampliado pelas suas colocações próximas aos ícones culturais ou literários. Ao incluir figuras de várias épocas, lugares e posições, a capa implica que este tipo de coleção não pode representar a realidade. Ao notarmos quem constitui o grupo, imediatamente reconhecemos a impossibilidade de este evento ter acontecido. Além disso, a fotomontagem desestabiliza a "hierarquia" entre as pessoas mostradas porque elas existem essencialmente ao nível de um jogo. Nenhuma figura usurpa o lugar da outra; embora algumas estejam escondidas, Blake observa que isso ocorreu para enfatizar o efeito de realidade ao invés de se tornar uma afirmação sobre quem é mais importante ou influente. Assim, o status de contribuição se torna praticamente irrelevante na determinação de valor ou importância. Sekula observa que as fotos adquirem um novo significado quando são coletadas e montadas, uma vez que "layout, legendas, texto, local e modo de apresentação" afeta como o observador as vê. Após absorvemos este novo contexto, nos recuperamos do "choque da montagem" (SEKULA, 1987, p.117) porque perdemos o significado ou contexto original. SEKULA (1987, p.127) argumenta que precisamos ler os arquivos "de baixo para cima" porque "nem o conteúdo nem a forma, nem as muitas recepções e interpretações do arquivo das conquistas humanas podem ser tomadas como inocentes". Embora não estejamos discutindo aqui 0 arquivo genuíno, ainda podemos ler os elementos da fotomontagem de Sgt. Pepper como um tipo de arquivo popular, uma vez que propõe um tipo de engajamento 
similar com a maneira como as imagens podem ser privadas do seu significado "inerente".

Outra forma como a fotomontagem faz sua crítica de representação é através da relação e posição dos Beatles em meio às figuras. A própria inclusão dos Beatles entre outras pessoas, coloca todos no mesmo nível cultural. Ao mesmo tempo em que o momento histórico se torna irrelevante, também se torna o "trabalho" ou ocupação. Em outras palavras, os Beatles se tornam profissionais da cultura e figuras políticas da mesma forma que Bob Dylan ou Karl Marx já haviam se tornado. Mais interessante do que isso, entretanto, é o fato de que os Beatles não são fotografias recortadas, mas pessoas "reais": mesmo as estátuas de cera foram colocadas em frente às colagens de fotografias. A pura complexidade da imagem e as representações dos Beatles dentro do grupo (podemos dizer que três: como figuras em cera, como membros da Banda do Sgt. Pepper e como artistas invisíveis representados pelas flores que escrevem seu nome) exercem uma crítica de sua própria imagem. Entretanto, também faz a crítica à maneira como os Beatles se tornaram ícones e celebridades prontas para serem comercializadas. Ou seja, como o álbum não é simplesmente uma fotografia dos membros de uma banda, ele sugere duas coisas. Primeiro, este tipo da capa era inadequada para comunicar uma mensagem política. Segundo, era uma época de críticas ao conceito de mercadoria. De certa maneira, os Beatles exploraram a ideia de mercadoria - um conceito que discutirei mais detalhadamente quando examinar a relação entre a capa e a arte pop - que se constituem em um embrulho cuidadoso e cheio de artimanhas. Entretanto, a utilização de fotomontagem se alinha com a crítica do consumo por meio de sua aliança com a esquerda cultural - uma associação que já estava estabelecida. Assim, a utilização da fotomontagem permite uma crítica da representação (como Ades e Berger discutem), assim como a crítica da política de identidades e o papel da mercadoria na sua moldagem.

\section{3 - Pop Art e a crítica do bem de consumo}

Como a fotomontagem, a pop art foi, em grande parte, uma resposta às condições políticas e sociais da Inglaterra do pós-Guerra, compartilhando com a fotomontagem as mesmas tendências esquerdistas. Como uma "rebelião contra a arte estabelecida" (LIVINGSTONE, 1991, p.146), a pop art teve temas duradouros como sexo, tecnologia, entretenimento e cultura de massa. Iniciada por um grupo de artistas no London College of Art na década de 1950 chamado de Independent Group, a pop art se tornou uma resposta às formas de arte burguesas que necessariamente emfatizavam a "hierarquia de valores formulados pelas classes superiores (LIVINGSTONE, 1991, p.146). Os membros mais antigos do Independent Group - incluindo aí Richard Hamilton e Peter Blake - eram ideologicamente compromissados com a missão da pop art e firmes nas suas declarações, em uma "linguagem direta e franca nascida do impulso democrático que sacudia a sociedade em que viviam (LIVINGSTONE, 1991, p.146). Nesse aspecto, a pop art também compartilha com a fotomontagem o compromisso de fazer uma arte que respondesse à necessidade de uma reforma social, assim como explicitar observações agudas sobre a política social.

Mas a arte pop é diferente da fotomontagem por diversas razões, sendo a maior delas o fato de abertamente celebrar a cultura popular. Essa celebração não deve ser confundida como "as decodificações semiológicas dos subtextos sociais, políticos ou econômicas do imaginário popular" (LIVINGSTONE, 1991, p.147) - que a fotomontagem faria - mas, ao contrário, enfatiza a produção tecnológica de objetos do dia a dia. A arte pop se inicia, de fato, com uma exposição de Richard Hamilton, chamada "Just what is it that makes today's homes so different, so appealing?" ["0 que tornam as casas de hoje tão diferentes, tão atraentes?"], exposição que introduziu as fontes materiais da arte pop: fotografia, televisão, propaganda, quadrinhos, cinema, revistas de fisioculturismo, produtos de consumo e nomes de marcas (LIVINGSTONE, 1991, p.148). Com o objetivo de prover uma "visão caleidoscópica da cultura", esta exposição (e a arte pop em geral) permitiu um olhar sobre os produtos as experiências do dia a dia, apresentando-os como espaços de crítica, ironia e, mesmo, paródia. Dentro da arte pop reside, assim, uma crítica inerente. Seu objetivo era, tanto para artistas quanto para o público, não apenas ver os objetos do dia a dia como "arte", mas também exercer uma crítica de antigas tradições da arte estabelecida. LIVINGSTONE (1991, p.160) observa que, em uma entrevista, Andy Warhol declarou que queria ser uma máquina e não um artista, porque as máquinas eram capazes de reproduzir uma miríade de imagens que eram exatamente iguais, 0 que era um elemento central na mensagem de Warhol. Ele queria expor as formas em que a arte poderia ser produzida, reproduzida, manipulada, retiradas da seara burguesa para se encaixar no estilo de vida urbano.

Peter Blake, artista com a fascinação de Warhol em mente, tinha uma relação única com a arte pop. Em uma entrevista com Mervyn LEVY (1963, p.185), Blake admite que, para ele, arte pop "geralmente tem raizes na nostalgia: a nostalgia de coisas antigas e populares. Embora eu fique tentando criar uma nova arte pop, uma que reflita o meu tempo, me pego olhando para as fontes dessa linguagem". 0 comentário de Blake representa um ponto chave para boa parte da comunidade da arte pop, embora essa posição tenha sido revista por membros mais populares, à medida que o movimento progrediu. A nostalgia de Blake o inspirou a incluir cartões-postais, fotografias, itens comprados em lojas ou encontrados em suas composições - itens que não revelam de modo algum a presença de seu trabalho manual como artista. LEVY (1963, p.185) resume a visão artística de Blake: ". . para Blake, arte pop, como a música pop, é fundamentalmente uma ilusão. Ambas manifestações se preocupam com os estados de ilusão gerados pelo que é popular, sons e imagens, respectivamente". A ênfase na ilusão revelaria o processo por meio do qual a arte é criada, sendo 
que o desejo pelo que é popular resulta da linguagem democrática e de cultura de massa que músicos e artistas compartilhavam. Mas a autoavaliação de Blake sobre seus projetos também abre uma nova janela para o ideário dos artistas pop: a arte poderia ser apreciada por qualquer um, especialmente os jovens porque, na sua visão, eram, segundo ele, mais receptivas às inovações apresentadas pela música pop e mais conscientes das condições sociais em torno do surgimento da arte pop.

A associação de Blake como os Beatles se originou no início de suas carreiras, muita antes de eles se tornarem superstars. Como Blake havia estabelecido a conexão entre arte pop e música pop, ícones da música eram frequentes no seu trabalho. LEVY (1963, p.188) diz que Blake considerava os Beatles como ícones do pop: "Os Beatles simbolizam a vasta cultura popular a partir da qual a arte pop deriva suas fontes de inspiração". No seu primeiro projeto para os Beatles, mantida ao nível de uma conversa apenas, Blake queria enfatizar a conexão entre eles e seu ambiente urbano - Liverpool - bem como comunicar a ideia do "significado visual que, de certa forma, equivale à atmosfera dos Beatles" (LEVY, 1963, p.187). Podemos antever como a visão de Blake se amalgama com o impulso do Sgt. Pepper, pois a capa do álbum, como Sorger e Jones nos lembra - essencialmente "vende" e reflete a atmosfera, as nuanças e qualidade da música que contem. Embora a peça de 1963 de Blake sobre os Beatles não fosse uma capa de álbum, a utilização de artistas de música pop e sua arte antecipam a confluência de ícones populares com figuras históricas, políticas e sociais na capa do Sgt. Pepper. Como Blake estava tão comprometido com a "admass" nostálgica - um termo que Levy emprega para descrever a visão dos artistas pop, se referindo à propaganda da cultura de massa - faz sentido ver que ele escolheu para os Beatles o que é, talvez, o seu mais famoso trabalho.

A ideia de nostalgia é um componente natural da identidade de performance dos Beatles. Sua dupla aparição na capa pode sugerir uma reconfiguração complexa de sua imagem profissional, assim como uma nostalgia complexa de seus primeiros dias como artistas, ingênuos e despreocupados. Podemos ver isso representado pelos bonecos de cera dos Beatles justapostos aos seus equivalentes em carne e osso, contemporâneos e psicodélicos. A justaposição dos membros "reais" da banda (embora fantasiados) com os modelos de cera em tamanho real chama atenção não apenas para a revisão de suas identidades, mas também para as maneiras como a imagem dos Beatles se tornou um bem de consumo. Tomo as palavras de Womack and Davis, de que os Beatles "remitologizaram" a sua imagem no Sgt. Pepper, brincando com sua identidade enquanto mercadoria; com o foco na maneira como a música e o álbum interage. Assim, volto ao que acredito ser o mais importante aspecto da capa do disco em relação à arte pop: a crítica do bem de consumo.
Como William NORTHCUTT (2006, p.132) observa, os Beatles em Sgt. Pepper ". . . sentiram as contradições inerentes à sua parte no espetáculo: protestavam contra aspectos do capitalismo ao mesmo tempo em que promoviam um produto de imagem e música para ser vendida e aceita". Isso descreve com precisão a maneira como o álbum zomba e subscreve, embora divertidamente, ao fetiche do consumo. É importante observar que a utilização da arte pop enfatiza essa associação, uma vez que o manifesto da arte pop parece fazer o mesmo tipo de crítica ideológica. 0 pacote do disco é a associação mais clara com a arte pop e com o engajamento e crítica dos Beatles, ao considerar a gravação como bem de consumo.

NORTHCUTT (2006, p.135-136) observa que "o invólucro do Sgt. Pepper, sua capa dupla, seus encartes com dobraduras e letras impressas foram os primeiros na indústria do disco, e representaram o primeiro esforço orquestrado para vender o produto para as massas". Entretanto, ele argumenta que "as letras das músicas impressas na capa indica uma autoconfiança dos Beatles enquanto artistas e indica um desejo de pregar para as massas: elogiar ou condenar o seu papel no espetáculo". Podemos partir dessas observações sobre o invólucro do álbum para ilustrar a complexa relação da capa com o bem de consumo. Cada uma de suas inovações foi um tributo à fascinação da arte pop com a vida cotidiana e com a cultura do consumo embora, como um todo, essas inovações fizessem muito mais do que apenas "vender" a banda. Ao contrário, a inovação sem precedentes da capa, sua "novidade" e, por que não dizer, choque de valores, também requeria que o consumidor fosse um participante ativo na sua mensagem.

Assim como o painel de figuras se tornou um exercício intelectual, convidando o expectador/ouvinte a "entrar" na imagem, as dobraduras dos encartes e capa dupla do disco prontamente chama para um tipo de ação semelhante. As dobraduras dos encartes, além disso, são autônomas e existem independentemente do disco, pois podem ser utilizadas para outros propósitos além do escutar e do olhar. Ao incluir "brinquedos" como parte do pacote, os Beatles não apenas fazem uma crítica do consumo, mas também forçam o álbum a ocupar o mesmo "espaço" ou posição da arte pop. Em outras palavras, a associação com a arte pop já havia sido reconhecida e, ao ser comprado, o Sgt.Pepper poderia ser considerado uma peça de arte. Além disso, a arte pop também convidava seu público/consumidores a criticar o cotidiano da mesma forma que o oferecia para venda.

Não há dúvida que Sgt.Pepper é oferecido como produto de consumo, pois em última análise, é um disco de música. Poderíamos dizer que a capa é, de fato, um acessório à música, e que compartilha uma relação simbiótica com as inovações das canções dos Beatles e suas inclinações políticas. Mesmo se este for o caso, devemos reconhecer que incluir dobraduras e artifícios 
óbvios - um novo tipo de dobradura, as letras na capa, as cores berrantes e os "novos" Beatles - requer um tipo de consciência que não pode ser desprezado. 0 próprio invólucro do disco enquanto invólucro e o novo tipo de gravação de áudio contribuem para a crítica do consumo, uma vez que perguntam implicitamente ao consumidor 0 que estão comprando. Os consumidores estão comprando o álbum pela música? Pelos seus artifícios? Pelo seu choque de valores? Pela sua associação com os Beatles? Pela sua diferença dos antigos Beatles? A questão se torna irrelevante; o que interessa é que, por meio do excesso visual e compromisso geral em subverter o status quo, a capa do álbum demanda uma cooperação e uma participação do consumidor de uma maneira que as capas de álbuns anteriores não faziam. Assim como o exercício intelectual de identificação das figuras na colagem como pano de fundo se tornou um jogo intelectual e, assim, um convite para o expectador/ouvinte entrar na experiência visual da capa do álbum, o empacotamento e o re-emolduramento de identidades da mesma forma empurra o expectador/ouvinte para o seu próprio tipo de autocrítica. A associação com a art pop só fez aumentar essa autorreflexão, pois era óbvio que, na época, artistas pop como Peter Blake estavam levantando questões dessa natureza no seu trabalho.

\section{4 - Alta cultura e baixa cultura}

Defendi neste artigo que Sgt. Pepper marca um momento definitivo das capas de álbuns e, mesmo, da história, pois exerceu, em diversas camadas, uma crítica de representação. Agora, quero problematizar esta leitura ainda mais sugerindo que, se formos reconhecer 0 potencial crítico da capa deste álbum, devemos considerálo separadamente do contexto da cultura popular. Não quero dizer com isto que a capa do álbum não funciona na seara popular, muito menos que não é primariamente um objeto concebido para o consumo em massa. Ao contrário, sugiro que Sgt. Pepper, e as capas de discos em geral, deveriam ser lidas como textos com ligações proeminentes e irrevogáveis às críticas de status quo de maneira semelhante ao que a teoria crítica coloca.

Em The Rest of you, if you just rattle your jewelry: the Beatles and questions of mass and high culture, Paul GLEED (2006, p.161) observa que "a música dos Beatles foi, em resumo, arte de alto nível para o público de massa". Se esta afirmação pertence especificamente a musica que fizeram, podemos vê-la também como pertencente às capas de álbum também. Ele sugere que esta observação "parece representar o jeito predominante de compreender a posição dos Beatles entre 'o pessoal dos ingressos baratos' e 'o resto' " (GLEED, 2006, p.161). Além disso, os Beatles podem ser "vistos como instrumentos para desafiar e dissolver categorias tradicionais e restritivas como 'arte de alto nível' e 'cultura de massa' " (GLEED, 2006, p.162), porque trabalharam ativamente para realizar sua música
- e sua mensagem - acessível a todos os públicos. As opiniões sobre seus papéis nesse processo, mais evidentes na capa do Sgt. Pepper, deixam claro sua crítica geral sobre categorias adjetivadas como alta e baixa.

Embora a distinção de Gleed sobre arte de alto nível e arte popular pareça suficiente, Leslie Fiedler também oferece evidências para considerarmos artefatos populares com capas de álbum com espaços de crítica. No seu ensaio seminal Cross the border, close the gap, ela comenta que

\begin{abstract}
transformar Arte de Alto Nível em vaudeville e burlesca, no mesmo instante em que a Arte de Massa está irreverentemente adentrando museus e bibliotecas é um ato que tem implicações políticas e estéticas: como um ato que interrompe uma categoria [um corte], assim como um hiato entre gerações. . . o que a intromissão final do Pop nas searas da Arte de Alto Nivel propicia, por isso, pois para os críticos existem uma nova e emocionante possibilidade de fazer juízos sobre o "bom" e o "ruim" da arte, sem ter de fazer distinções entre "alto" e "baixo" dentro de seu preconceito de classes dissimulado" (FIEDLER, 1997, p.287).
\end{abstract}

Fiedler observa como textos ou artefatos populares parecem resistir às classificações simplórias, pois frequentemente são percebidas por públicos que estão fora de seu contexto original. Este é exatamente o cenário da pop art, o que faz com que muitos artistas pop lamentem que sua crítica seja abrandada por sua inclusão em museus e cooptados pelos padrões de gosto da burguesia que, essencialmente, a transformaram em mercadoria (LIVINGSTONE, 1991, p.150). Fiedler também chama a atenção para a inadequação de categorias binárias como "bom" e "ruim" ou "alto" e "baixo", sugerindo que, ao contrário, eles façam suas avaliações estéticas sem considerar essas categorias como informativas ou relevantes.

GLEED (2006, p.163), diz que a avaliação de Fiedler da situação pós-moderna tem uma grande dívida com os Beatles: "o ponto, é claro, não é que as mudanças no pensamento cultural, a dissolução entre as fronteiras entre a 'alta' cultura e a de 'massa' foram inteiramente dirigidas pelos Beatles, mas que ninguém mais pode dizer que fez mais para criar aquele ambiente". Observando que "os Beatles trabalharam de baixo para cima. . . a partir de uma posição popular", GLEED (2006, p.164), aponta o momento de Sgt. Pepper como aquele no qual as distinções entre que as culturas "de massa" e a cultura "de alto nivel" convergiram, uma vez que a crítica estava tão entranhada na música que era impossivel ignorá-la. 0 mesmo também se aplica à crítica - vinda de baixo, com de fato foi - entrincheirada em cada faceta da arte de fazer capas de discos: fotomontagem, pop art e comprometimento com o produto comercial. Como tem sido por 40 anos desde o lançamento do álbum, devemos estar atentos às nossas próprias crenças em relação ao legado dos Beatles. É neste momento que reavaliações de valor e categorias se mostram mais relevantes. 


\section{Referências}

ADES, D. Photomontage. London: Thames and Hudson, 1976.

THE BEATLES. Sgt. Pepper's Lonely Hearts Club Band. Primeira edição em 1967. Parlophone, 1987 (Disco de áudio).

BLAKE, P. Liner Notes. In: Sgt. Pepper's Lonely Hearts Club Band. Com The Beatles. Primeira edição em 1967. Parlophone, 1987 (Disco de áudio).

FIEDLER, L. Cross the Border, Close the Gap. In: The Fiedler Reader. New York: Stein and Day, 1977.

GLEED, P. The Rest of You, If You'll Just Rattle Your Jewelry: The Beatles and Questions of Mass and High Culture. In: Reading the Beatles: Cultural Studies, Literary Criticism, and the Fab Four. Ed. Kenneth Womack e Todd F. Davis. Albany: State University of New York Press, 2006.

GLOAG, K. Situating the 1960s: Popular Music-Postmodernism-History. Rethinking History. V.5, n.3, 2001. p.397-410. All You Need is Theory? The Beatles' Sgt. Pepper. Music \& Letters, v.79, n.4, 1988, p.577-83.

HARRY, B. The Beatles Encyclopedia. London: Virgin Publishing, 1992. p.969-979.

INGLIS, I. "The Beatles Are Coming!": Conjecture and Conviction in the Myth of Kennedy, America, and the Beatles. Popular Music and Society. v.23, n.1, 1999. p.93-108.

"Nothing You Can See that Isn't Shown": The Album Covers of the Beatles. Popular Music. v.20, n.1, 2001. p.83-97.

JONES, S.; SORGER, M. Covering Music: A Brief History and Analysis of Album Cover Design. Journal of Popular Music Studies. 1999. p.68-103.

LEVY, M. Peter Blake: Pop Art for Admass. Studio International. n.847, 1963. p.184-189.

LEWIS, M. Sgt. Pepper's Lonely Hearts Club Band. Variety 100. 16, October, 2005. www.variety.com/index. (Acesso em 27 de março, 2006).

LIVINGSTONE, M. Pop Art: An International Perspective. London: Royal Academy of Arts Press, 1991.

MOORE, A. F. The Beatles: Sgt. Pepper's Lonely Hearts Club Band. Cambridge: Cambridge University Press, 1997.

NORTHCUT, W. M. The Spectacle of Alienation: Death, Loss, and the Crowd in Sgt. Pepper's Lonely Hearts Club Band. In: Reading the Beatles: Cultural Studies, Literary Criticism,

and the Fab Four. Ed. Kenneth Womack e Todd F. Davis. Albany: State University of New York Press, 2006. p.129-146.

SEKULA, A. Reading an Archive. Blasted Allegories. Ed Brian Wallis. MIT Press, 1987. p.114-127.

WOMACK, K.; DAVIS, F. T. Mythology, Remythology, and Demythology: The Beatles On Film. In: Reading the Beatles: Cultural Studies, Literary Criticism, and the Fab Four. Ed. Kenneth Womack e Todd F. Davis. Albany: State University of New York Press, 2006. p.97-110.

\section{Referência adicional}

GOLDMAN, Albert. The Lives of John Lennon. New York: William Morrow and Co., 1988.

SGT. PEPPER COVER CHARACTER SEARCH. In: http://www.peppercover.com (Acesso em 1 de março, 2013)

\section{Notas}

1 Concebido como um jogo online, o site Sgt. Pepper Cover Character Search (http://www.peppercover.com) permite a identificação de todas as figuras e principais objetos utilizados na capa de Sgt Pepper.

2 Nota do Tradutor: Inicialmente, a ideia era usar as flores na sessão de fotos marcada para a noite. Como os Beatles desmarcaram o encontro, muitas flores não resistiram e o que sobrou foi arranjado por uma assistente da floricultura na forma de um violão (GOLDMAN, 1988, p.260).

3 As escolhas dos personagens por cada um dos Beatles foi muito diferente: George Harrison incluiu gurus indianos desconhecidos; a de John Lennon, a mais excêntrica, incluiu Jesus (não aprovado devido ao famoso incidente anterior em que Lennon disse que os Beatles eram mais populares do que o principal ícone do cristianismo) e Hitler; Paul McCartney se concentrou em instrumentos musicais e Ringo preferiu não nomear ninguém (GOLDMAN, 1988, p.259).

Sarah Etlinger é Professora de Composição, Literatura e Comunicação na Rocky Valley College (Illinois,EUA). Possui Ph.D em Retórica e Composição (2012), com foco em estudos de novas mídias, pela University of Wisconsin-Milwaukee (EUA), Mestrado em Inglês pela Syracuse University (EUA), onde foi bolsista, e Bacharelado em Inglês pelo Skidmore College (EUA). Publicou, anteriormente, duas resenhas sobre os Beatles, um de seus temas favoritos, juntamente com novas mídias e cultura popular. Atualmente, desenvolve pesquisa relacionando o iTunes e a aprendizagem de retórica por estudantes.

Fausto Borém é Professor Titular da UFMG, onde criou o Mestrado e a Revista Per Musi. Pesquisador do CNPq desde 1994, publicou dois livros, três capítulos de livro, dezenas de artigos sobre práticas de performance e suas interfaces (composição, análise, musicologia, etnomusicologia da música popular e educação musical) em periódicos nacionais e internacionais, dezenas de edições de partituras e recitais nos principais eventos nacionais e internacionais de contrabaixo. Recebeu diversos prêmios no Brasil e no exterior como solista, teórico, compositor e professor. Editou os números 22, 23, 28, 29 e 30 da Revista Per Musi, conjunto com mais de 1.000 páginas de trabalhos acadêmicos dedicados à pesquisa sobre música popular. 